\title{
A REVIEW ON SANDWICH BEAM
}

\author{
Rizwana Ali \\ Department of Mechanical Engineering \\ Sri Sant Gadge Baba College of Engineering And Technology, \\ Bhusawal, Maharashtra, India \\ A.V. Patil \\ Department of Mechanical Engineering \\ Sri Sant Gadge Baba College of Engineering And Technology, \\ Bhusawal, Maharashtra, India
}

\begin{abstract}
The paper represents the review of sandwich beam used in the structure. The sandwich beam taken under consideration for review is metal with rubber, FRP, Neoprene, etc. The review finds that the sandwich beams are more resist to vibration than the other regular metal or nonmetal beam.
\end{abstract}

Keywords - Sandwich beam, FRP beam, metal and non metal sandwich beam etc.

\section{INTRODUCTION}

Composite or Sandwich structures are most prime research areas for today's researcher. The field of composite materials is one of the most successful areas of research. Lots of literature is available in this field. Many researchers discuss about the shear deformation effects and then compare it with numerical methods. The composite layer gives a viscoelastic effect to the beam. The strength gets increase; flexibility get increase more over this the damping capacity get increase with some composite materials. That's the reason maximum researcher is trying $t$ find the best possible composite structure for the applications. There is lots of scope available in the field of composite materials as the field is developing with new possibilities. In this paper the scope is limited to the different viscoelastic material for beam.

The methodology used for review is in following ways. Firstly, data collection related to topic completed from the, research gates and from other digital library of research paper. The research paper downloaded was 80 in numbers and then after reading and sorting the necessary paper as per the topic was shortlisted and only 22 research paper was shortlisted for the research paper. The research paper was reviewed from last ten years.

\section{REVIEW OF LITERATURE}

1. Manish Kumar et.al.[1] developed the software which is simple in use to analyze the sandwich beam. The author did the validations of the software reading with ANSYS. In this work, inspect the activity of sandwich beams, which had driven by the viscoelastic rubber core. Finite element method (FEM) used to analyze the static responses harmonic responses, transient responses, of the sandwich systems.

2. Prathameshet.al.[2] investigate a beam with four cracks for finding they're dynamic characteristics of. An efficient approach had made in the present investigation to develop a model and simulate for evaluation of natural frequencies and mode shapes of fixed-fixed and a cantilever beam. A FEM model being developed for the composite beam of three layers.

3. N. Jacques et .al.[3] studied geometrically nonlinear vibrations of sandwich beams with viscoelastic materials. For this purpose, a new finite element formulation has developed, in which a zigzag model is used to describe the displacement field. The viscoelastic behavior had handled by using hereditary integrals and their relationships with complex moduli. The author prepared the solution procedure, which was based on the harmonic balance method. To demonstrate its abilities, various problems of nonlinear vibrations of sandwich beams are considered.

4. V.N. Burlayenkoet.al.[4] deliberate that analysis of plates using finite element vibration analysis become one of the classical problems over the past several decades. 


\section{International Journal of Engineering Applied Sciences and Technology, 2019 \\ Vol. 4, Issue 6, ISSN No. 2455-2143, Pages 230-233 \\ Published Online October 2019 in IJEAST (http://www.ijeast.com)}

Different finite element plate models based on classical, standard and improved shear deformable plate theories, three-dimensional elasticity equations or their combinations have developed.

5. Dvir Elmalich, et.al.[5] studies the effect of the inter-laminar contact and its temporal variation on the behavior of FRP strengthened walls with delaminated regions. The paper adopts an analytical approach that unifies the displacement and stress fields of sub-regions where the delaminated faces are in contact with ones where the layers are free of contact.

6. M. R. Doddamani, et.al.[6] studied the dynamic analysis of jute-epoxy sandwiches with fly ash reinforced functionally gradient (FG) flexible, compliant rubber core is presented. By using conventional casting technique, a sample of FG was being prepared. Presence of gradation been quantified by weight method. The design of experiments based upon L9 (33) orthogonal arrays by Taguchi is used. Analysis of variance (ANOVA) and S/N (signal to noise) ratios analysis been performed on measured data, which examine the impact of geometrical as well as material parameters on dynamic response.

7. Dr.P.S.Senthil Kumar [7] studied the damping characteristics of Hybrid polymer composite, which can be used in many applications and in engineering structures. The investigation aims to develop glassepoxy composite with the addition of carbon (600mesh) fillers with different weight fractions and to characterize the mechanical and damping properties. The hand Lay-up and vacuum bag molding procedure is used on carbon filler to fabricated and reinforce. The features of damping estimated by using forced and free vibration test with different amplitudes. The result shows that with an increase in weight percentage of carbon reinforcement content the features or damping characteristics are improved.

8. D.J.connor [8], uses built up element technique for the finite element analysis of sandwich beam. A computer-based program had built for the investigation of sandwich beam. The method built up technique gives a versatile methodology of modeling.

9. Waldir Neme Felippe Filho [9], conducted an experiment on viscoelastic sandwich beam and then compare with numerical method
GHM (Golla, Hughes and Mc Tavish method) to validate the result. The numerical method was used to understand the dynamic properties of viscoelastic material. The experiment studied several beams with and without viscoelastic material. It has found that the structure with viscoelastic material shows that passive control significantly improves the damping ratios of beam. The experimental result and GHM result shows close tolerance therefore the model is useful for simulating sandwich beam.

10. RupaliR.Chavan [10] studies the composite materials strength to weight ratio and find that the composite material are ease of fabrication, having good electrical and thermal properties as compared to metals. Several beam is modeled with varying core thickness under fixed and fixed cantilever boundary conditions for modal analysis. An FEM model of sandwich is prepared with three-layer viscoelastic material. The natural frequencies help to understand the value of core thickness and the result been then compared to experimental results.

11. Hwai-Chung $\mathrm{Wu}[11]$ composite beam with FRP is common is structure buildings. It failure depends on the modelling interface. Here the sandwich panel was modelled which constrain a smooth stress from the skins to core. The failure behavior of beam had compared with numerical predictions and experiment.

12. Ziad K. Awad[12]developed a new glass fibre reinforced polymer (GFRP). It study the behaviour of single and glue laminated GFRP sandwich beams using 3D non linear FEA method. It uses FORTAN language for UMAT subroutine, which includes had model for 3D analysis. The result then compares with the experimental analysis.

13. Y.P Ravitej [13] studied the properties of mild steel rubber sandwich beam specimens with variable thickness of core. The model is analysed in Ansys with 3 point bending test.

14. Ana Cristina Galucio [14] presents a FEA formulation for transient dynamic analysis of sandwich beam with viscoelastic material by using fractional derivative constitutes equation. The equation is prepared using Timoshenko theory and Euler-Bernoulli assumptions. The equation of motion was solving by a direct integration method based on implicit newmark scheme. 


\section{International Journal of Engineering Applied Sciences and Technology, 2019 \\ Vol. 4, Issue 6, ISSN No. 2455-2143, Pages 230-233 \\ Published Online October 2019 in IJEAST (http://www.ijeast.com)}

15. [15-17] studied the building structure with composite material. The structure develop were sandwich panels, pultrusion and plates. The FRP materials based model is prepared and analysis done using FEA method. The two-dimensional (2D) and three-dimensional (3D) simulations had done.

16. [18-20], studied the multi layer composite beam using FEA method. The simulation of the beam is prepared by using 3D composite solid element. In the same manner some experiments were performed using GFRP sandwich panels.

17. Awad et al. [21] prepared the simulation of GFRP that help to understand the behavior using numerical simulation method.

18. Awad et al.[22] used the 2D Hashin model to simulate the GFRP skin with a CRUSHABLE foam model for simulating the core behaviour. The result been compared with the experimental data and it shows the good agreement with GFRP.

\section{DISCUSSION AND CONCLUSION}

Sandwich beams which are the answer to many structural problems demanding self-control and flexible characteristics involving mechanical and thermal stresses. As the advent of steel changed the last century, similarly these beams which will revolutionize the 21 st century. If the concentration of vibration reduced in the structure, then more quit operations can occur. Therefore, the composition of two or material to form a structure leads to a less vibrant system. There is a huge scope in a combination of metal to rubber, neoprene, FRP and many more. These are less discussing in literature and should used for research work.

The conclusion behind the review is that the world need more optimize and less vibrant equipment. Therefore, composite structure needed to get more damped and more valuable structure for the equipment. The composite structure with metal to rubber, neoprene and FRP gives more damped and light weight structure. The review can be used to work on vibration control structure with composite materials.

\section{REFERENCES}

[1]. Manish Kumar, Earnest Vinay Prakash, Prabhat Kumar Sinha and Avinash Shilpi, To study analysis of sandwich beam with Ansys and fem, International Journal of Information Research and Review Vol. 2, Issue, 07, pp. 947-951, July, 2015.

[2]. Prathamesh, Prabhat Kumar Sinha, earnest vinay Prakash, Analysis and study the effect of crack on the dynamic characteristic of the beam through Ansys International Journal of Engineering Research-Online Vol.3., Issue.5., 2015 (Sept.-Oct.)

[3]. N. Jacques, , E.M.Daya, M.Potier-Ferry, Nonlinear vibration of viscoelastic sandwich beams by the harmonic balance and finite element methods, Journal of Sound and Vibration 329, 4251-4265, (2010)

[4]. V.N. Burlayenkoa,n, H.Altenbach b, T.Sadowski, An evaluation of displacement-base finite element models used for free vibration analysis of homogeneous sand composite plates, Contents lists available at Science Direct Journal of Sound and Vibration

[5]. Dvir Elmalich, Oded Rabin ovitch, On the effect of inter-laminar contact on the dynamics of locally delaminated FRP strengthened walls, International JournalofNonLinearMechanics77(2015)141-157

[6]. M. R. Doddamani, S. M. Kulkarni, Dynamic response of fly ash reinforced functionally graded rubber composite sandwiches - a Taguchi approach, International Journal of Engineering, Science and technology vol. 3, No. 1, 2011, pp. 166-182

[7]. Dr.P.S.Senthil Kumar, Karthik.K,Raja.T, Vibration Damping Characteristics of Hybrid Polymer Matrix Composite, International Journal of Mechanical \& Mechatronics Engineering IJMME-IJENS Vol:15 No:01 153101-8282-IJMME-IJENS (C) February 2015 IJENS I J E N S.

[8]. D.J.Connor, A Finite Element Package for the Analysis of Sandwich Constructions, composite Structures 8 (1987) 143-161.

[9]. Waldir Neme Felippe Filho, Flávio de Souza Barbosa, Ney Roitman, Carlos Magluta, Flávia Carolina Borges, Experimental and numerical evaluation of viscoelastic sandwich beams, REM, Int. Eng. J., OuroPreto, 70(3), 281-287, jul.sep. | 2017, http://dx.doi.org/10.1590/037044672013700015

[10]. Rupali R.Chavan, P. S. Talmale, Free Vibration analysis of FRP Base Composite Sandwich Beam using FEA: A Review, International Journal of Engineering Science and Computing, March 2017, Volume 7 Issue No.3, 4901-4904

[11]. Hwai-Chung $\mathrm{Wu}, \quad \mathrm{Bin} \mathrm{Mu}$, Kraig Warnemuende, Failure analysis of FRP sandwich 


\section{International Journal of Engineering Applied Sciences and Technology, 2019 \\ Vol. 4, Issue 6, ISSN No. 2455-2143, Pages 230-233 \\ Published Online October 2019 in IJEAST (http://www.ijeast.com)}

bus panels by finite element method, Composites: Part B 34 (2003) 51-58

[12]. Ziad K. Awad, ThiruAravinthan, Yan Zhuge, Finite Element Analysis Of Glass Fibre Reinforced Polymer Single And Glue Laminated Sandwich Beams Under Four Point Bending, Research in Civil and Environmental Engineering 20142 (01) 24-44

[13]. Y.P Ravitej, SwaroopV, Ramesh S,Adarsha $\mathrm{H}$, Veerachari, Nischith, Finite element Analysis of mild steel - rubber sandwich composite material, IOP Conference Series.: Material Science and Engineering, 2018, 376012040

[14]. Ana Cristina Galucio, Jean-François Deü, Roger Ohayon, Finite element formulation of viscoelastic sandwich beams using fractional derivative operators, Computational Mechanics, Springer Verlag,2004, 33, pp.282 - 291. Doi: 10.1007/s00466-003-0529-x. hal-01422435

[15]. HooFatt, M.S.\&Pothula, S.G., Dynamic pulse buckling of composite shells subjected to external blast, Composite Structures, (2010). 92(7), 1716-1727.

[16]. Kollár, L.\&Springer, Mechanics of composite structures, G. Cambridge Univ Pr. (2003).

[17]. Roy, T., Manikandan, P.\&Chakraborty, D.Improved shell finite element for piezo thermoelastic analysis of smart fiber reinforced composite structures, Finite Elements in Analysis and Design, (2010). 46(9), 710-720.

[18]. ABAQUS Hibbitt, Standard user's manual, Karlsson \& Sorensen Inc. (2008).

[19]. Panigrahi, S.K.\&Pradhan, B., Through-thewidth delamination damage propagation characteristics in single-lap laminated FRP composite joints, International Journal of Adhesion and Adhesives, 2009, 29(2), 114-124.

[20]. Pyo, S.\&Lee, H.,Micromechanics-based elastic-damage analysis of laminated composite structures, International Journal of Solids and Structures, (2009), 46(17), 3138-3149.

[21]. Awad, Z.K., Aravinthan, T.\&Manalo, A., Geometry effect on the behaviour of single and glue-laminated glass fibre reinforced polymer composite sandwich beams loaded in four-point bending, Materials \& Design, 2012, 39(0), 93103.

[22]. Awad, Z.K., Aravinthan, T.\&Zhuge, Y, Experimental and numerical analysis of an innovative GFRP sandwich floor panel under point load, Engineering Structures, 2012, 41(0), 126-135. 